tion of an analytical process in a standard work of reference is based upon multiple analyses in one laboratory: other workers, whose laboratories are possibly less exactly controlled, may show much poorer agreement through no fault of their own. Dr. Davies agreed that different laboratories often show appreciable differences in standard analyses. Dr. Finney emphasized the need for remembering that any standard deviation relates to the variation from a particular set of causes, and may well fail to characterize the dispersion of actual observations when additional sources of variation are introduced. Mr. Bacharach argued strongly that new standard analytical techniques ought to be studied collaboratively in several laboratories; he also reminded the audience that outliers should never be rejected without examination of causes, for observations that were apparently anomalous have often been the start of great new developments. Mr. Smart quoted an instance of a set of two hundred observations that conformed excellently to a normal (Gaussian) distribution if six extreme values were rejected; Dr. Finney maintained that this in itself did not justify the rejection unless there were strong a priori reasons for believing that the true distribution was normal.

Mr. Senior asked for advice on the sampling of very valuable material, for which the actual cost of the portion used in analysing a sample might be important. Dr. Davies suggested that the difficulty could be removed by the chemist devising techniques for the analysis of very small quantities. Dr. Wood pointed out that the policy to be adopted must be determined on economic grounds: if decisions of great monetary or other importance depend upon reliable analytical information, even large expenditure on sampling may be a desirable measure of insurance against grave errors.

Several other inquiries related to the sampling of continuous processes. Mr. Hewitt asked about the frequency with which indicators of a process ought to be read in order to provide adequate evidence of whether or not the process is in control. Mr. Soper suggested standard quality-control practices of intensifying observations when the control is under suspicion. Dr. Davies said that observations must be frequent enough to detect fluctuations of a size that would be important to the process, and that only by knowledge of the process could any more exact guidance be given. Dr. Wood warned against dependence on observations at regular intervals of time, regular in relation to shifts, or in any other way likely to be related to periodicities in the process, since periodic changes might impair the validity of estimates of variability; Dr. Finney directed attention to the non-independence of successive observations on a continuous process and the possibly autoregressive character of the errors.

In reply to a question from Mr. Berkovitch about the number of levels of various factors to be used in a factorial experiment for the estimation of optimal conditions, Dr. Wood suggested that three or four levels of each factor usually suffice. Dr. Finney thought that many factors at two levels each might be used in a preliminary trial, and those that were found most important might later be tested more intensively, at three or four levels each, over a narrower range. Dr. Davies again emphasized the great advantages of a sequential steepest-ascent investigation where this is practicable. Mr. Berkovitch also suggested that extrapolation from a set of observations, in spite of its logical and theoretical flaws, may legitimately be used to indicate useful Iines for further experimentation; Dr. Finney fully agreed that this is valuable and certainly permissible provided that the extrapolations are not regarded as established before experiment has confirmed or refuted them. Mr. Soper suggested that time ought often to be regarded as a factor in an investigation, and all experiments repeated at two or three distinet times, since extrapolation in time is essential to the usefulness of any inferences drawn.

D. J. FINNEY

\section{NATIONAL INSTITUTE FOR RESEARCH IN DAIRYING, SHINFIELD REPORT FOR 1950}

$T$

HE farm must obviously be the site of much of the experimental work of a research organization such as the National Institute for Research in Dairying, Shinfield, and in the annual report for 1950 , which has recently been published*, it is made clear that the farm is the important background of much of the laboratory work. The Institute has two farms, covering about seven hundred acres, with more than two hundred head of cattle-largely Shorthorns but with some Friesians and Guernseys. As in many other agricultural research centres, some devolopments, particularly those involving buildings, are unavoidably slow, and preparation for them occupies a lot of the time of the staff. But within these limits the work of the farms is very progressive, including the implementing of $a$ well-defined breeding programme and the careful cataloguing of all records that may conceivably be needed in the interpretation of experimental results.

Besides maintaining the essential work and records of the farms as such, the Dairy Husbandry Section has a good deal of experimental work to its credit, including a continuation of studies of the rates of milking, of the suitability of certain fodder crops for milk production, and various experiments on the rate of growth and milk yields of pigs.

For some years the Institute has been concerned with factors affecting the efficiency of the use of food by ruminants, and the experimental work has lately been much facilitated by the design of a harness for the satisfactory separation of the urine and the frecs of the dairy cow. Much of this work has since been published. In the recent work it has been found that the softening of finely divided hay (as opposed to long hay) by grinding in the mouth reduces the ability to regurgitate. Initiation of the regurgitation reflex his, however, sometimes been brought about by appropriate hand-scratching.

It has been found that diets low in roughage cause a reduction in fat yield but do not affect the percent. age of non-fatty solids. The properties of butter were affected, too, by low roughage diets, the butter having a higher percentage of unsaturated acids and a low softening point.

The report for last year called in question the use of lignin as a 'reference' substance in studying rates of digestion. The validity of using lignin depends

- University of Reading : National Institute for Research in Dairying. Report for 1950. Pp. 103. (Shinffeld: National Institute for Research in Dairying, 1951.) 38 . 
on the assumption that it is not digested; but recent work at the Institute has shown that the results of the estimation of lignin digestion can differ considerably according to the method used, and also by the same method according to differences in composition of the diet. The lignin ratio technique is therefore suspect.

The important work following the recent demonstration of ostrogen in British pasture is continuing in conjunction with the Courtauld Institute of the Middlesex Hospital. While otstrogenic activity was marked in grasses in 1949, there was little in 1950 , and attention has been given to broad red clover, the ostrogen content of which seems to be more consistent. The work has been largely directed to the identification and separation of the active substances and to their occurrence, distribution and physiological action. Isolation is proving a difficult problem, but work is being pursued with a good hope that oestrogenic substances will be identified without isolation by a radioactive isotope method.

Work continues on the effects of different levels of œstrogen on mammary growth-rates in rats. American work having shown that a deficiency of folic acid restricts the effects of oestrogen in growthrates in other connexions, the effect of administering a folic acid antagonist is being investigated in this work. While it is well established that aminopterin has a pronounced effect on body growth in general, nothing specific to mammary growth has yet been found.

The continued study of the synthesis of the fatty acids of milk from acetate (using sodium acetate with radioactive carbon in the carboxyl group) gives further evidence of the view that short-chain acids are intermediate in the formation of long-chain acids from acetate and emphasizes the importance of fattyacid synthesis in the udder from small molecules. The belief that the utilization of acetate for milk fat synthesis takes place in the udder itself has been substantiated by experiments in which reactions in the liver and elsewhere were excluded.

Bacteriological work is involved in a large number of investigations, and the bacteriological examination of the milk produced on the farm has been systematically carried out. The Institute has co-operated in the work of a committee appointed by the Ministry of Agriculture to examine the resazurin and methylene blue tests, and investigations have been carried out into faults in cream and sterilized milk. The study of the classification of streptococci and lactobacilli continues to occupy several members of the staff. Work on the problem of fat absorption by the cup liners of milking machines, referred to in a previous report, has been finished, and the incorporation into the linings of a proportion of synthetic fatresistant rubber has been shown to be possible.

Some interesting work is in progress on the role of micro-organisms in the synthesis of $B$ vitamins in the rumen. Straw pulp, alkali-treated straw, hay and concentrates showed, in the order named, decreasing amounts of vitamin complex synthetized and a correlated decrease in the number of micro-organisms in the rumen fluid and on the food.

There is a good deal of work on the effects of antibiotics. The effects of certain antibiotics in accelerating growth in normal chicks have been confirmed. With chicks deficient in animal protein factor, however, this stimulation only occurred with vitamin $B_{12}$, which can presumably replace the other components of the animal protein factor. In work on the production of antibiotics, no streptococci outside the lactic group have yet been found with antibioticproducing power.

Study of the physical properties of cheese has suggested some practical tests for quality assessment. The physical and rheological properties of butter have been claiming attention, but the work has not yet reached a stage for report.

The proteins of milk are the subject of a number of investigations. Work connected with the inactivation of lysine during the storage of dried skim milk gives support to the view that lysine is not essential for maintenance in rats. The preheating of milk under pressure before spray-drying did not seem to affect either the biological value or the digestibility of the protein. There is evidence that vitamin $\mathbf{B}_{12}$ is in. volved in protein metabolism : the biological value of casein fed to chicks without $B_{12}$ was $82 \cdot 2$; with vitamin $B_{12}$ it was $89 \cdot 7$.

The testing of all kinds of equipment is a continual concern of the Engineering Department. The work there, however, is not confined to routine ; it includes studies of the electronic treatment of milk and of boiler water and the ultra-violet irradiation of milk. In much of this work the staff are in close contact with workers in other countries.

Reference can only be made in this short account to some of the work being done; but these references will show the kind and the diversity of the work, and a catalogue of it can be seen in the list of ninety-five publications appended to the report.

\section{MELLON INSTITUTE, PITTSBURGH ANNUAL REPORT FOR 1950-51}

THE thirty-eighth annual report of the president of the Mellon Institute, Dr. E. R. Weidlein, to the board of trustees, published under the title "Current Scientific Researches in Mellon Institute, 1950-51"*, covers the year ended February 28, 1951. During this year the Institute's building was completed, including new executive offices, a new periodical room for the library and a new conference room.

In the Department of Chemical Physics a collaborative programme on the properties of synthetic rubber, initiated under the ægis of Multiple Fellowships, designed to study the infra-red spectra of rubber-like polymers, has already shown that sometimes both cis. and trans-polyisoprenes are produced by the same biological plant. A special Weissenberg camera and a Laue camera have been designed and built for the crystal study at temperatures down to that of liquid nitrogen of compounds normally liquid or gaseous at room temperature. Research in physical chemistry has been principally in the theory of distillation, including a completed study of the performance of intermittent take-off heads for distillation columns. In the Department of Organic Chemistry work has persisted on diabetes caused by alloxan, and work on the biochemistry of mental diseases has tentatively confirmed the hypothesis that the urine (and, presumably, the blood) of some patients contains a pathological constituent, suggesting that the patients also suffer a metabolic or endocrine disturbance. Two series of pteridine derivatives were in the course of being studied-one related to folic

* Current Scientific Researches in Mellon Institute, 1950-1951: the Thirty-eighth Annual Report of the President, $\mathbf{E}$. R. Weidlein, to the Board of Trustees of the Institute for the Fiscal Year ended February 28, 1951. Pp. Iv +52. (Pittsburgh, Pa. : Mellon Institute, 1951.) 